\title{
Research on the Application of New Media in the Design of English Writing Program
}

\author{
Tian'e Huang ${ }^{1, a}$, Sumin $\mathrm{Ma}^{2, \mathrm{~b}}$ \\ ${ }^{1}$ Hebei University of Economics and Business, Shijiazhuang, 050061, China \\ ${ }^{2}$ Hebei University of Economics and Business, Shijiazhuang, 050061, China \\ a email: hte0588 @163; bemail: msm1997@163.com,
}

\section{Keywords: New Media; Application; Designing English writing program; EFL Teaching}

Abstract. It's widely acknowledged that the application of new media on the design of English writing program in EFL Teaching turns out to be a great progress. Research on new media application in this area mainly focuses on aspects: automatic evaluative system, automatically-generated writing corpus, interactive system between evaluation and revision in synchronous computer-mediated communication. This research aims to investigate how to incorporate these three aspects into a comprehensive program design.

\section{Introduction}

New media refer to wireless networks, communications equipment, and some new media forms such as digital newspapers and periodicals, digital television, digital movie, mobile-phone message and WeChat, MicroBlog, e-mail or QQ and so on, supported by digital and Internet technology and taking advantage of local area network. The characteristics of the new media are instant, interactive, integrating, sharing and plentiful etc[1]. Especially in EFL teaching, the advantage of the new media is increasingly obvious. For example, Blackboard online classroom, online composition correction, some online vocabulary software, wireless Internet English resources are widely used in EFL teaching.

The application of new media in education is one of its most important application areas, especially its application on designing English writing program. There has been more than 60 years since foreign professional software developers have thought about applying computer technology on designing a computer-assisted writing program. Their efforts created the software products like EG (Project Essay Grade), IEA(Intelligent Essay Assessor) and E-rater complete with our domestic web writing software like Juku and Lange writing system[2].

Despite the evolutionary developments in the application of new media on designing English writing program, there is little report on any revolutionary changes in writing system that might have resulted from systematic inquiry into these areas. New media may in the future radically change research and practice in the design of English writing program but doing so will require the type of research that engages with the complexity of the issues [3], crossing the boundaries between technology writing, language, and for the purpose of developing paths that work toward the goals of technology application and applied linguistics.

Therefore, it is necessary integrate the professional knowledge of professional software developers and education experts to design a more comprehensive writing program. Based on a thorough investigation on how new media are applied on designing English writing program, here comes the conclusion that natural language processing technology, statistics, and artificial intelligence are the basis for designing such a comprehensive program.

As for its function design, the new program should put emphasis on realizing the following functions: automatic evaluative system, automatically-generated writing corpus, interactive system between evaluation and revision in synchronous computer-mediated communication. At present, some writing programs, for example, Automatic Essay Scoring can realize peer interactive evaluation, while, the evaluation result was only limited to a score or a little prescriptive comments. But their comments, which might serve as important supporting evidence, enabling the evaluated student to reflect upon how to make revision, are usually left untreated. Therefore, it is expected that in the new 
design there could be a kind of technological function embedded in the automatic evaluation system help generating peer comments corpus spontaneously.

So this paper investigates the most needed new media for designing a new English writing program. They include the application of computer technologies like automatic generating corpus, corpus linking and trans-corpus searching and classifying.

\section{Design of English Writing Program}

\section{Automatic Evaluative System}

The existing automatic evaluation systems mainly focus on the evaluative function from 2 aspects: form and content. By comparison, content evaluation appears to be relatively weaker than form evaluation. On one hand, it is relatively difficult to standardize the variable thoughts and ideas, measuring which one is more superior. On the other hand, there lacks technology supports for recognizing writers' stylistic features, which can be regarded as belonging to the part of developing artificial intelligence, a rather complex area, waiting to be developed.

But in reality there indeed exists some thinking patterns that can help novice and intermediate-level English learners organize ideas and make their expression of thought easily get across. That's why most education experts believe writing programs are more suitable for novice and intermediate-level of English learners. In order for the program to be really effective, it is advisable to integrate into the program the following searching functions [4]:

First, an English-English dictionary includes reference notes, example sentences and a verb conjugation. Second, three references: a vocabulary index that contains topical vocabulary lists, a grammar index that contains fundamental explanations of grammar points, and a phrase index, a listing with examples of language functions. Third, the searching menus in the writing stage mainly include 3 parts as shown by Figure 1:

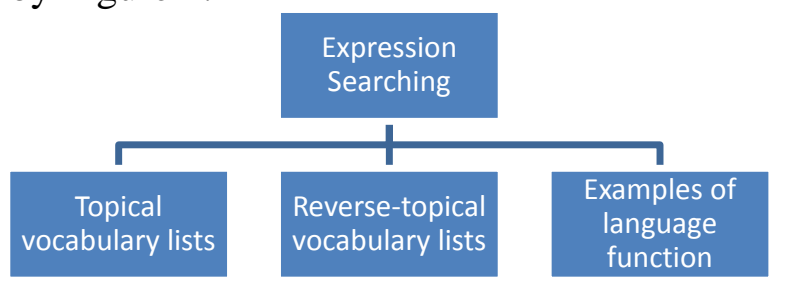

Figure 1

These sets are mainly for helping novice writer internalize the proper expression form and appropriate word or phrases for one particular idea. As for the intermediate-level learners, there needs topical vocabulary lists and reverse-topical vocabulary lists and examples expression lists of certain language functions, which provide rich input materials for students to diversify their expression, and then form a healthier writing habits directly, hence, reducing the negative interference of their native language.

After accomplishing the writing task in the program independently, there at once comes the automatic evaluation result, by which writers can rethink and reshape their writing. However, sometimes there might be obscure feedbacks from the evaluation system that students cannot understand by themselves. So it's necessary for learners to have timely communication with someone who might help. Peer interactive synchronous conferencing can serve as an important compensation for this limitation.

\section{Synchronous Conferencing System}

Synchronous conferencing system, taking the form of e-mail or QQ group, provides a convenient platform for users to communicate ideas among their learning community. It's hoped that e-mail and QQ group functions can be embedded in the writing program so that there would be easier to record the real communication of ideas and meta-cognitive process of their mutual evaluation, and finally collect a kind of multiple-perspective evaluation with special value.

Besides, the interactive functions of web-logs facilitate computer-mediated peer reviews for collaborative writing [5]. The membership of peer group can be extended to include their foreign counterparts whose native language or second language is English [4]. 
However, here usually arises another problem. What if the synchronous conferencing exchanges in written language meet with some socio-culturally different understanding [4]? Wouldn't it be a consideration if the system could spare a special function area, where "written speakers" can jot down their instant puzzles? These speedy notes too could be saved as journal files and automatically generate a tiny self-reflection corpus. Therefore, the design of future English writing program is expected to possess the following functional menus:

Table 1: The Writing Screen

\begin{tabular}{|l|l|l|}
\hline Writing & Evaluation & Conferencing \\
\hline Topic list & Anti-topic list & Functional expression list \\
\hline Writing area & cancel \\
\hline save &
\end{tabular}

Table 1 is the user interface of the writing system where learners can type in their writings. While the folded materials in sub-menus can facilitate the fluency of appropriate expression, enhancing writers' confidence and making them spare more energy concentrating on writing out more creative ideas. All writings could either be saved or cancelled.

Table 2: The Evaluation Screen

\begin{tabular}{|l|l|l|}
\hline Writing & Evaluation & Conferencing \\
\hline Writing file & Auto-evaluation file & Teacher evaluation file \\
\hline $\begin{array}{l}\text { Peer-evaluation } \\
\text { file }\end{array}$ & BNC corpus & Self-reflection \\
\hline Peer & Teacher & Speedy Notes \\
\hline Written communication area & \multicolumn{2}{|l}{ cancel } \\
\hline \multicolumn{2}{|l}{} \\
\hline
\end{tabular}

Table 2 is the user interface of the evaluation system where writers can make comments about any saved piece of writing in the written communication area; jot down their puzzles about various evaluations coming from different resources. Also their comments could either be saved or cancelled.

Table 3: The Conferencing Screen

\begin{tabular}{|l|l|l|}
\hline Writing & Evaluation & Conferencing \\
\hline Writing file & Auto-evaluation file & Teacher evaluation file \\
\hline $\begin{array}{l}\text { Peer-evaluation } \\
\text { file }\end{array}$ & BNC corpus & Self-reflection \\
\hline \multicolumn{2}{|l|}{ Written communication area } & cancel \\
\hline \multicolumn{2}{|l|}{ save }
\end{tabular}

Table 3 is the user interface of the synchronous conferencing system where both any user can have written conference with reference to various collective files. Each written speakers' remarks could either be saved or cancelled by themselves. More importantly, the linkage to the Web literal materials like the BNC corpus, encourage greater cognitive processing of errors [6], giving conferencing participants another standard to re-evaluate their supposition about the excellent writing, thus involving all participant in the interactive communication of exploring and constructing knowledge of the English language as well as the most appropriate ways of expressing and spreading ideas.

Therefore, the guiding principle of the new program design is to enable users to engage in discussions and collaborative writing activities with others on the basis of tangible materials since each user could have at least one focused, intense peer-response experience that parallels what writers outside of the classroom typically experience[7], each new message that was added to a particular discussion become automatically available to all participants, who could consider it and comment upon it as they wished. 
Many learners who have using experience of English writing programs felt that the skills gained from synchronous conferencing would be usable in future career and appreciated the wide range of learning possibilities provided by advanced computer technology[4]. So the beneficial results of applying computer technology in designing English writing program, such a small area, are not only confined to promoting teaching technology but also extended to change user's vision of future development. It's a worthwhile career.

\section{Spontaneously Generating Corpus}

From the above design, it's not difficult to find new media material files serve as important input resources, preparing for improving users' expressing ability, either in the form of composition or in the form of written conversation. In essence, they are also kinds of feedback, when technically combined with powerful searching engines; make sure to impress users with a systematic idea on how the expressional form of thought should be arranged. In addition, when applying the searching function with "theme" as its key word, different writings with the same theme could be quantitatively collected, which provide evidence for users figuring out the trace of their own Interlingua development.

Another desirable technical support for spontaneously generating corpus is inter-corpus searching function. Users can find similar feedback from the automatic evaluation system; peer and teacher conferencing as well as their own self-reflection bank so that they could easily have the distinct impression about the most appropriate expression forms. Therefore, corpus-based research should focus on maximizing the learner's developmental potential by developing more advanced corpus systems and enhancing the learner's textual awareness and analytical ability [8].

\section{Conclusion}

In conclusion, the future English writing program design with the above desirable functions needs improved new media technology supports like advanced web-based linking technology, technology support for spontaneously generating corpus, for inter-corpus searching and international spontaneous conferencing. It helps realize a combination of activities stressing both creative conversational writing and attention to fluent and logical expression necessary to promote the development of users' writing proficiency [4].

\section{Acknowledgement}

In this paper, the research was sponsored by 2014 Higher Education English Teaching Reform Project in Hebei Province with the title "Research on EFL Teaching Mode in the Circumstances of New Media” (Project No. 2014YYJG029), by the 2015 Teaching Research Project of Hebei University of Economics and Business with the title "Research on Building the College English Blackboard Online Classroom and Teaching Resources Sharing" (Project No. 2015JYY11) and by 2015 Higher Education Scientific Research Project of Hebei Province with the title "Research on Efficiency of EFL Classroom Teaching in Information Age” (Project No. GJXH2015-65).

\section{References}

[1] Ban Bei, Strategies of Traditional EFL Classroom Reform in the Circumstances of New Media. [J]. English Square. NO. 2 (2015), pp. 97.

[2] Liang Mao-cheng; Weng Qiu-fang, A Comprehensive Study of Foreign Writing Automatic Assessing Systems and Their Enlightenment. [J]. CAFLE No. 117 Oct 2007 .

[3] Baker, F. B. (1989). Computer Technology in Test Construction and Processing. InR. L. Linn (Ed.) Educational Measurement, 3rd edn. NY: Macmillan Publishing Co. pp. 409-28.

[4] Alice Omaggio Hadley. Teaching Language in Context[M]. Foreign Language Teaching and Research Press: Beijing.2003.

[5] Liou, Hsien-Chin;Peng, Zhong-Yan.Training Effects on Computer-mediated Peer Review.[J]. System.2009.

[6] Alex Gilmore.Using Online Corpora to Develop Students' Writing Skills[J]. English Language Teachers Journal. 2009.

[7] Strasma, Kip."Spotlighting": Peer-Response in Digitally Supported First-Year Writing Courses [J]. Teaching English in the Two-Year College. 2009. 
[8] Kwanghyun Park.Learner-Corpus Interaction: A Locus of Microgenesis in Corpus-assisted L2 Writing [J]. Applied Linguistics.2012. 